\title{
CAPACIDADE AUTODEPURATIVA DO CÓRREGO DO LIMOEIRO APÓS LANÇAMENTO DE EFLUENTE TRATADO
}

Tamíris Silva Corrêa ${ }^{1}$

Renata Ribeiro de Araújo ${ }^{2}$

Márcia Aparecida da Silva ${ }^{3}$

\begin{abstract}
RESUMO
Os corpos d'água têm capacidade de recuperar-se naturalmente após receberem certa quantidade de matéria orgânica, entretanto essa capacidade é limitada e dependente de vários fatores, processo denominado de autodepuração. Assim, tem-se como enfoque a análise da capacidade autodepurativa do Córrego do Limoeiro, corpo hídrico de classe 4, localizado no município de Presidente Prudente SP, após lançamento de efluente tratado. Tal estudo está baseado na modelagem matemática Streeter \& Phelps (1925), cuja aplicação depende do monitoramento de variáveis limnológicas. Estas variáveis são demanda bioquímica de oxigênio (DBO), oxigênio dissolvido $(\mathrm{OD})$, temperatura e vazão (Q). Foram também obtidos o pH e a demanda química de oxigênio (DQO). Para isso, foi realizada uma amostragem dessas variáveis em 3 seções do Córrego do Limoeiro (a montante do lançamento do efluente tratado; a jusante do lançamento; e a uma distância de mais de $9 \mathrm{~km}$ do despejo), e 1 seção na saída do efluente tratado (Calha Parshall). Os resultados mostraram que o córrego apresenta capacidade suporte para o esgoto tratado que recebe, porém não recupera completamente suas características iniciais. No trecho analisado, o corpo d'água está de acordo com o previsto para cursos hídricos classe 4, segundo o Decreto 10.755/77 e a Resolução Conama 357/05.
\end{abstract}

PALAVRAS-CHAVE: Autodepuração. Córrego do Limoeiro. Modelagem Streeter \& Phelps.

\section{LEMON TREE CAPACITY OF STREAM AUTODEPURATIVA TREATY WASTE AFTER LAUNCH}

\begin{abstract}
Water bodies are able to recover naturally after receiving certain amount of organic matter, however this capacity is limited and dependent on many factors and this is called self-purification. So, it is necessary to approach the analysis of self-purification capacity of the Limoeiro Stream, water body class 4, located in the city of Presidente Prudente - SP, after release of treated effluent. This study is based on mathematical modeling Streeter \& Phelps (1925), which application depends on the monitoring limnological variables. These variables are biochemical oxygen demand (BOD), dissolved oxygen (DO), temperature and flow rate (Q). The $\mathrm{pH}$ and chemical oxygen demand (COD) were also obtained. For this, sample collection of these variables was performed in 3 sections of the Limoeiro stream (upstream of the release of treated effluent; downstream of the release, and at a distance of more than $9 \mathrm{~km}$ from the dumping), and one section of the effluent output treated (Parshall Gutter). The results showed that the stream has capacity to support the treated sewage which it receives, but

\footnotetext{
${ }^{1}$ Graduanda em Engenharia Ambiental, Universidade Estadual Paulista "Júlio de Mesquita Filho", Campus de Presidente Prudente. tamirissc@yahoo.com.br.

${ }^{2}$ Profa. Dra. Do Departamento de Planejamento, Urbanismo e Ambiente, Universidade Estadual

Paulista “Júlio de Mesquita Filho", Campus de Presidente Prudente. reribeiro@fct.unesp.br.

${ }^{3}$ Mestre em Geografia, Programa de Pós-Graduação em Geografia/ Mestrado Profissional da Universidade Estadual Paulista "Júlio de Mesquita Filho", Campus de Presidente Prudente.marcia3210@hotmail.com.
} 


\section{Periódica Eletranica

does not completely recover its initial characteristics. Over this stretch, the water body is in accordance with the arrangements for water resources Class 4, according to the Decree 10,755 / 77 and the CONAMA Resolution 357/05.

\section{LEMON TREE CAPACIDAD DE RESIDUOS TRATADO AUTODEPURATIVA STREAM DESPUÉS DE SU LANZAMIENTO}

\section{RESUMEN}

Se puede observar que los ríos presentan una capacidad de recuperación natural después que reciban una descarga de material orgánico, que se puede denominar autodepuración. Todavía, esta capacidad es limitada y dependiente de un gran cantidad de factores. Así, en este trabajo se analiza la capacidad de autodepuración del "Córrego do Limoeiro", un río categoría 4, ubicado en la ciudad de Presidente Prudente (SP), después que de la liberación de efluente tratado en el río. El estudio esta basado en el modelo Streeter \& Phelps (1925), cuya aplicación depende del control de una serie de variables limnológicas. Las principales son: Demanda Bioquímica de Oxígeno (DBO), Oxígeno Dissolvido (OD), Temperatura y caudal del río (Q). El grupo también obtuvo la Demanda Química de Oxígeno (DQO) y pH. Por ello, fueran realizadas amostrajes en 3 puntos ubicados en el "Córrego do Limoeiro" (antes de la liberación del efluente tratado, después de la descarga y $9 \mathrm{~km}$ después de la liberación) y un punto en que se obtuvo las características del efluente tratado liberado en el río. Con los resultados, ha sido posible verificar que el río soporta la liberación del efluente, pero no vuelve a su condición inicial. Es posible verificar una adecuación de la calidad del agua para ríos categoría 4 en toda la parte analizada (Decreto 10.755/77 y Resolución CONAMA 357/05).

\section{INTRODUÇÃO}

Os corpos d'água, após a introdução de determinada quantidade de matéria orgânica, conseguem se recuperar através de meios naturais, porém essa capacidade é finita e depende das características do próprio corpo d'água, além de depender também da quantidade de matéria orgânica introduzida. Essa recuperação é denominada de autodepuração do corpo d'água. (MOTA, 2003).

Antes do lançamento dos dejetos, o ecossistema do curso d'água encontrase geralmente em estado de equilíbrio e após a entrada da fonte poluidora as comunidades são afetadas em alto grau, resultando numa desorganização inicial, seguida por tendência posterior à reorganização. (VON SPERLING, 2005, p. 137).

Muitos fenômenos contribuem para a autodepuração de um curso d'água entre eles estão fatores físicos como a diluição, turbulência da água, sedimentação, temperatura, luz solar, reaeração atmosférica, fatores químicos como reações de oxidação e redução, fatores biológicos como a decomposição. (BARRUS, 2009).

Ao longo do perfil longitudinal do corpo d'água diferenciam-se quatro zonas de autodepuração que são a zona de degradação, a zona de decomposição ativa, a zona de recuperação e a zona de águas limpas. 


\section{Periádica Eletrânica

A montante do lançamento de despejos tem-se a zona de águas limpas, caracterizada pelo seu equilíbrio ecológico e elevada qualidade da água, em geral é uma região com elevada concentração de oxigênio dissolvido e vida aquática superior (VON SPERLING, 2007).

A zona de degradação é aquela que se inicia a partir do ponto no qual há o lançamento de efluentes no curso d'água, ela tem como característica a alta concentração de matéria orgânica. Os microrganismos após se adaptarem as condições existentes nessa zona, atingem a taxa máxima de consumo da matéria orgânica, acarretando na taxa máxima de consumo de oxigênio dissolvido (predomínio de bactérias aeróbias) (FREIRE, 2008). A DBO atinge seu valor máximo no ponto de lançamento e a partir daí começa a decrescer.

$\mathrm{Na}$ zona de decomposição ativa, os microrganismos ainda estão em fase de decomposição da matéria orgânica, a qualidade da água está em seu pior estado, com coloração acentuada e podem ser vistos os depósitos de lodo no fundo. O oxigênio dissolvido atinge sua menor concentração e a DBO continua a cair.

A zona de recuperação se caracteriza pela matéria orgânica apresentar-se grandemente estabilizada, a qual foi consumida de modo muito intenso anteriormente, assim, o consumo de oxigênio pela respiração bacteriana é reduzido. Devido a este último fato, e a introdução de oxigênio atmosférico, os teores de oxigênio dissolvido aumentam, pois sua produção pela reaeração atmosférica é superior ao consumo necessário para a estabilização da matéria orgânica (FREIRE, 2008).

$\mathrm{Na}$ zona de águas limpas as águas apresentam-se limpas e suas características anteriores ao lançamento de esgoto estão novamente presentes, pelo menos quanto à matéria orgânica e quanto aos teores de bactérias e oxigênio dissolvido. É importante salientar que apesar de na zona de águas limpas a água tenha recuperado muitas de suas características, algumas mudanças ocorreram de forma permanente, como o aumento dos compostos inorgânicos (nitratos, fosfatos e sais dissolvidos) que criam um ambiente ideal para a proliferação intensa de algas. Ainda nesta zona, a diversidade de espécies volta a ser grande, a cadeia alimentar é restabelecida e o ecossistema será novamente estável (MOTA, 2003).

Para que se possa controlar o lançamento de efluentes que estejam acima da capacidade de assimilação do corpo d'água, é de fundamental importância 
quantificar e compreender o fenômeno de autodepuração descrito anteriormente. (VON SPERLING, 1996 apud ANDRADE, 2010). A modelagem da qualidade da água foi desenvolvida com vistas a facilitar a resolução de problemas como esse.

A modelagem de qualidade da água possibilita a simulação de autodepuração de um rio, além da observação do padrão de qualidade da água de um corpo hídrico ao receber algum tipo de poluição, da avaliação e gerenciamento de diversos usos da bacia hidrográfica envolvida, evita grandes gastos com inúmeras análises e acidentes ambientais, diminui o tempo de observação que antes do modelo poderia demorar anos e procurar novas formas de conter algum incidente sem oferecer riscos ao meio ambiente e gastos desnecessários (ZUNTINI, 2012).

Uma dessas modelagens é a de Streeter \& Phelps (1925), cujo interesse é definir os impactos e as variações, pelas quais é submetida, em função do tempo e da posição, a concentração de determinada carga de poluentes (SANTOS, 2001 apud NUNES, 2008).

A hipótese básica da formulação matemática em questão é que os processos de decomposição da matéria orgânica no meio aquático e a reaeração pelo oxigênio atmosférico seguem uma reação de primeira ordem (BRAGA et al., 2003 apud SANTOS, 2010). O modelo de Streeter \& Phelps (1925) é uma reação de primeira ordem e está apresentada pela Equação 1.

$C_{t}=C_{s}-\left[\frac{K_{1} \cdot L_{0}}{K_{2}-k_{1}} \cdot\left(e^{-K_{1} \cdot t}-e^{-K_{2} \cdot t}\right)+D_{0} \cdot e^{-K_{2} \cdot t}\right]$

Na qual:

$C_{t}$ : Concentração de oxigênio ao longo do tempo $\left(\mathrm{mg} \mathrm{L}^{-1}\right)$;

$C_{s}$ : Concentração de saturação de oxigênio $\left(\mathrm{mg} \mathrm{L}^{-1}\right)$;

$L_{0}$ : Demanda bioquímica remanescente, no ponto de lançamento ( $\mathrm{mg} \mathrm{L}^{-1}$ );

$D_{0}$ : Déficit inicial de oxigênio dissolvido no curso de água $\left(\mathrm{mg} \mathrm{L}^{-1}\right)$;

$k_{1}$ : Coeficiente de desoxigenação $\left(\mathrm{d}^{-1}\right)$;

$k_{2}$ : Coeficiente de reoxigenação ou reaeração do rio $\left(\mathrm{d}^{-1}\right)$;

$t$ : Tempo (dias).

De acordo com a equação acima, é possível perceber que é de extrema importância compreender a influência das constantes $k_{1}$, $k_{2}$ e $k_{d}$ para a aplicação da modelagem e obtenção de resultados muito significativos. Tais constantes podem 
ser obtidas de muitas maneiras, de acordo com as características específicas do corpo d'água no qual está sendo realizado o estudo e as características da fonte de poluição que está sendo lançada nele.

Segundo Von Sperling (1996) apud Barros et al (2011), k é o coeficiente de desoxigenação e depende do corpo d'água estudado em termos de características da matéria orgânica, temperatura e presença de substâncias inibidoras. Braga et al. 2005 ainda complementa que esse coeficiente depende também das características do efluente que está sendo lançado.

Quanto ao coeficiente de remoção da DBO efetiva no rio $\left(k_{d}\right)$, Mourão Júnior (2010) explica que, em grande parte das vezes, em condições ambientes, a remoção da DBO resulta em valores maiores do que aqueles determinados laboratorialmente. De acordo com Chapra (1997) apud Mourão Júnior (2010), isso acontece devido à sedimentação da matéria orgânica e remoção da DBO pelo lodo do fundo; o coeficiente de remoção da DBO efetiva no rio $\left(k_{d}\right)$ inclui estes dois fenômenos de modo que $k_{d}$ (oxidação da DBO no curso d'água) $\geq k_{1}$ (oxidação da DBO em laboratório).

Esse fato está relacionado, principalmente, como explica Von Sperling (2007), à biomassa (bactérias) que cresce aderida a um suporte ser mais efetiva na decomposição da matéria orgânica do que aquela dispersa na massa líquida. "Como a conversão da DBO por esta biomassa aderida é exercida através da área de exposição, sua influência é mais pronunciada em rios rasos, pelo fato de se ter um menor volume de líquido por unidade de área" (VON SPERLING, 2007, p. 326).

A constante $k_{2}$, constante de reoxigenação do corpo d'água, depende da turbulência do meio, e "a seleção do valor desse coeficiente tem uma maior influência nos resultados do balanço do oxigênio dissolvido do que o coeficiente $\mathrm{k}_{1}$, pelo fato das faixas de variação do último serem mais estreitas" (SANTO, 2010, p. 66).

Os valores atribuídos a $\mathrm{k}_{2}$ podem ser encontrados de diversas maneiras, como através de métodos estatísticos que têm como entrada dados de OD em diversos tempos; valores médios tabelados, conforme mostra Von Sperling (2007); valores em função das características hidráulicas do copo d'água, por O'Connor \& Dobbins (1958), Churchill et al. (1982) e Owens et al. (apud Branco, 1978; Chapra, 
1997), Melching e Flores (1999); além de valores correlacionados com a vazão do curso d'água através de métodos de regressão.

Dependendo da situação na qual se está trabalhando, de acordo com Freire (2010) é importante realizar uma calibração do modelo. Isso significa aproximar os resultados modelados aos resultados encontrados nas análises laboratoriais, por meio da variação dos coeficientes de desoxigenação, de remoção da DBO efetiva no rio e de reoxigenação.

Ao se realizar um estudo de autodepuração, como no caso do córrego em análise, que recebe efluente tratado, tem-se a preocupação de descobrir se ele pode suportar a carga orgânica recebida. Isso é de fundamental importância para perceber quais as consequências da introdução do efluente tratado nas águas desse curso hídrico, ao longo do tempo e do espaço, o que também pode prejudicar outros corpos d'água nos quais ele tenha influência.

\section{OBJETIVOS}

Analisar o processo de autodepuração de um trecho do Córrego do Limoeiro, localizado no município de Presidente Prudente/SP, utilizando da modelagem Streeter \& Phelps (1925).

\section{METODOLOGIA}

Para o desenvolvimento da pesquisa foi realizado um monitoramento das variáveis limnológicas e hidrológicas, no trecho de interesse do Córrego do Limoeiro.

Durante os trabalhos de amostragem de água e coleta de dados realizados no trecho do córrego foram analisadas 4 seções conforme demonstra a Figura 1, sendo: as seções 1 e 2, como seções de monitoramento de variáveis de entrada para a modelagem Streeter \& Phelps (1925); seção 3 e 4 como seções de monitoramento de variáveis de controle para o mesmo modelo. 
Figura 1: Croqui da área de estudo

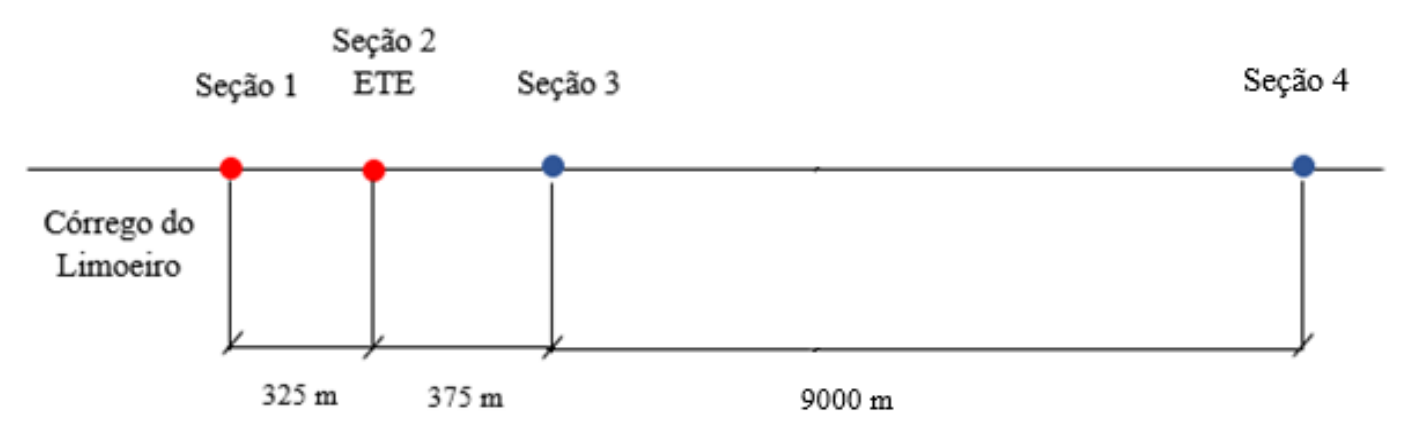

Legenda:

- Seções de entrada

- Seções de controle

Fonte: AUTOR, 2015.

Para as seções de entrada foram monitoradas as variáveis demanda bioquímica de oxigênio (DBO), oxigênio dissolvido (OD), temperatura, profundidade $(H)$ e velocidade (v) para posterior cálculo área da seção $(A)$ e da vazão $(Q)$. Já para as seções de controle foram monitoradas as variáveis demanda bioquímica de oxigênio (DBO), oxigênio dissolvido (OD). Também foram monitoradas em todas as seções, as variáveis potencial hidrogeniônico $(\mathrm{pH})$ e a demanda química de oxigênio (DQO). As metodologias empregadas estão descritas no Quadro 1.

Quadro 1: Variáveis e suas respectivas metodologias

\begin{tabular}{|c|c|c|}
\hline Variável & Unidade & Metodologia \\
\hline Temperatura & $\left({ }^{\circ} \mathrm{C}\right)$ & Termômetro \\
\hline DBO & $\left(\mathrm{mg} \cdot \mathrm{L}^{-1}\right)$ & Standard of Methods (1998) \\
\hline Profundidade & $(\mathrm{m})$ & Régua Métrica \\
\hline $\mathrm{pH}$ & - & Potenciômetro Digital Portátil \\
\hline Oxigênio Dissolvido & $(\mathrm{mg} / \mathrm{L})$ & Oxímetro Digital Portátil \\
\hline
\end{tabular}

Fonte: AUTOR, 2015

A determinação da vazão foi realizada da seguinte maneira: no primeiro momento, foi medida a largura total da seção e, a cada $1 \mathrm{~m}$, obteve-se a profundidade, com esse procedimento pode-se calcular as áreas parciais (para cada profundidade) e, pela soma delas, a área total da seção. 
Num segundo momento mediu-se com a trena uma distância de 1 metro e em seguida, posicionou-se um corpo flutuante no marco zero; com o auxílio de um cronômetro, contou-se o tempo para que esse corpo percorresse a distância dita. Tal procedimento foi realizado em triplicata, sendo que o valor que estava fora dos padrões foi descartado e aqueles próximos foram utilizados para a realização de médias aritméticas. Assim, com a Equação 2 abaixo foi calculada a velocidade.

$$
V_{m}=\frac{d}{t}
$$

Na qual:

$V_{m}$ : Velocidade média da água $(\mathrm{m} / \mathrm{s})$;

$d$ : Distância $(m)$;

$t:$ Tempo (s).

De posse da velocidade e da área da seção, a vazão foi encontrada através da Equação 3.

$$
Q=A * V_{m}
$$

Na qual:

Q: Vazão $\left(\mathrm{m}^{3} / \mathrm{s}\right)$.

Obtidas as características hidrológicas e limnológicas das seções de interesse do Córrego do Limoeiro, foram calculados os coeficientes de desoxigenação $\left(k_{1}\right)$, de remoção de DBO efetiva $\left(k_{d}\right)$ e de reoxigenação $\left(k_{2}\right)$, para a aplicação da Modelagem Streeter \& Phelps (1925).

Para a obtenção do coeficiente de desoxigenação $\left(k_{1}\right)$ e do coeficiente de remoção de DBO efetiva $\left(k_{d}\right)$, foram levadas em consideração as tabelas 1 e 2 respectivamente. $\mathrm{O}$ valor de $\mathrm{k}_{1}$ utilizado refere-se ao valor médio tabelado para efluente secundário, como é o caso do efluente tratado pela Estação de Tratamento de Esgotos Limoeiro, já para o $k_{d}$ foi o utilizado o valor máximo tabela para corpos d'água rasos recebendo efluente secundário. 
Tabela 1: Valores típicos dos coeficientes de remoção de DBO $\left(\mathrm{K}_{1}\right)$ (base e, $20^{\circ} \mathrm{C}$ ) Origem

Curso d'água recebendo esgoto bruto concentrado

$0,35-0,45$

Curso d'água recebendo esgoto bruto de baixa concentração

$0,30-0,40$

Curso d'água recebendo efluente primário

$0,30-0,40$

Curso d'água recebendo efluente secundário

$0,12-0,24$

Curso d'água com águas limpas

$0,08-0,20$

Fonte: VON SPERLING, 2007 (modificada)

Tabela 2: Valores típicos dos coeficientes de remoção de DBO (Kd) (base e, 20ํ)

Origem $\mathbf{k}_{\mathrm{d}}$

\section{Rios rasos Rios profundos}

\begin{tabular}{ccc}
\hline Curso d'água recebendo esgoto bruto concentrado & $0,50-1,00$ & $0,35-0,50$ \\
Curso d'água recebendo esgoto bruto de baixa concentração & $0,40-0,80$ & $0,30-0,45$ \\
Curso d'água recebendo efluente primário & $0,40-0,80$ & $0,30-0,45$ \\
Curso d'água recebendo efluente secundário & $0,12-0,24$ & $0,12-0,24$ \\
Curso d'água com águas limpas & $0,08-0,20$ & $0,08-0,20$ \\
\hline
\end{tabular}

Fonte: VON SPERLING, 2007 (modificada)

Para a compensação dos valores de $\mathrm{k} 1 \mathrm{e}$ kd para a temperatura obtida no monitoramento, foram utilizadas as equações 6 e 7 conforme descrito por Von Sperling (2007).

$k_{1 T}=k_{1,20} * 1,047^{(T-20)}$

$\mathrm{Na}$ qual:

$k_{1 T}: k_{1}$ corrigido para a temperatura $T\left(d^{-1}\right)$;

$k_{1,20}: \mathrm{k}_{1}$ a temperatura de $20^{\circ} \mathrm{C}$;

$T$ : Temperatura do curso d'água $\left({ }^{\circ} \mathrm{C}\right)$.

$k_{d T}=k_{d, 20} * 1,047^{(T-20)}$

$\mathrm{Na}$ qual:

$k_{d T}: k_{d}$ corrigido para a temperatura $T\left(d^{-1}\right)$; 
$k_{d, 20}: \mathrm{k}_{d}$ a temperatura de $20^{\circ} \mathrm{C}$;

$T$ : Temperatura do curso d'água $\left({ }^{\circ} \mathrm{C}\right)$.

Já para o coeficiente de reoxigenação $\left(\mathrm{k}_{2}\right)$, os valores numéricos podem ser obtidos das mais distintas formas. No caso das análises de autodepuração no Córrego do Limoeiro, optou-se pela aplicação da formulação de Owens et al. (apud Branco, 1978; Chapra, 1997), na medida que a sua validade para profundidade ( $0,1 m \leq H<0,6 m)$ e velocidade do curso d'água $(0,05 \mathrm{~m} / \mathrm{s} \leq V<1,5 \mathrm{~m} / \mathrm{s})$ eram compatíveis com as características hidráulicas do curso d'água em questão. Tal formulação matemática pode ser observada na Equação 8.

$k_{2,20}=5,3 * V^{0,67} * H^{-1,85}$

Na qual:

$k_{2,20}$ : coeficiente de desoxigenação a $20^{\circ} \mathrm{C}\left(\mathrm{d}^{-1}\right)$;

$V$ : Velocidade do curso d'água $(\mathrm{m} / \mathrm{s})$;

$H$ : Altura da lâmina d'água $(\mathrm{m})$.

Assim como as outras constantes, $\mathrm{k}_{2}$ também é afetado pela temperatura, e por isso, necessita de correção. A Equação 9 mostra como essa correção é realizada.

$k_{2 T}=k_{2,20} * 1,024^{(T-20)}$

Na qual:

$k_{2 T}: k_{d}$ corrigido para a temperatura $T\left(d^{-1}\right)$;

$k_{2,20}: k_{d}$ a temperatura de $20^{\circ} \mathrm{C}$;

$T$ : Temperatura do curso hídrico $\left({ }^{\circ} \mathrm{C}\right)$.

Para a aplicação da modelagem Streeter \& Phelps (1925), os dados foram tabulados em planilhas do software Excel for Windows 2013, segundo metodologia proposta por Von Sperling (2007).

Após o processamento da modelagem matemática foram plotados gráficos também no software Excel for Windows 2013 e de acordo com a metodologia do mesmo autor. 
De posse dos valores de OD e DBO encontrados para as seções de controle, tanto com a aplicação do modelo, quanto com a amostragem de água, pode-se calcular o erro obtido. Isso é importante para verificar a boa calibração da modelagem e pode ser realizado de acordo com a Equação 10.

$\%$ Erro $=\frac{\text { Valor }_{\text {calculado }}-\text { Valor }_{\text {amostrado }}}{\text { Valor }_{\text {amostrado }}} * 100$

Na qual:

\%Erro: Erro percentual da estimativa do modelo;

Valor $_{\text {calculado: }}$ Valor predito pela modelagem matemática;

Valor amostradoado: Valor da variável obtido no monitoramento.

\section{RESULTADOS E DISCUSSÕES}

Os resultados obtidos na amostragem das variáveis limnológicas e hidrológicas, bem como os laboratoriais estão dispostos nas tabelas 3 .

Tabela 3: Resultados do monitoramento das variáveis limnológicas e hidrométricas, utilizados para aplicação da modelagem Streeter \& Phelps (1925)

\begin{tabular}{ccccccc}
\hline Seção & $\begin{array}{c}\text { Área da } \\
\mathbf{s e c ̧ a ̃ o ~}\left(\mathbf{m}^{2}\right)\end{array}$ & $\begin{array}{c}\text { OD } \\
(\mathbf{m g} / \mathbf{L})\end{array}$ & $\begin{array}{c}\text { Temperatura } \\
\left({ }^{\circ} \mathbf{C}\right)\end{array}$ & $\begin{array}{c}\text { DBO } \\
(\mathbf{m g} / \mathbf{L})\end{array}$ & $\begin{array}{c}\text { Vazão } \\
\left(\mathbf{m}^{3} / \mathbf{s}\right)\end{array}$ & $\begin{array}{c}\text { Velocidade } \\
(\mathbf{m} / \mathbf{s})\end{array}$ \\
\hline 1 & 0,4356 & 8,00 & 27,5 & 9,00 & 0,1619 & 0,3717 \\
$2^{*}$ & & 4,61 & 31,1 & 9,00 & 0,600 & \\
3 & 1,8653 & 6,55 & 29,6 & 10,00 & 0,9055 & 0,4854 \\
4 & 0,725 & 6,38 & 28,3 & 8,00 & 0,2904 & 0,4005 \\
\hline
\end{tabular}

Fonte: AUTOR, 2015

* Os dados referentes à Seção 2, são aqueles do lançamento no córrego, ou seja, dados do efluente tratado.

Para a aplicação da Modelagem Streeter \& Phelps (1925), foram utilizados os coeficientes mostrados na Tabela 4. 
Tabela 4: Coeficientes utilizados na modelagem Streeter \& Phelps (1925)

\begin{tabular}{cc}
\hline Coeficientes de calibração do modelo & Valores \\
\hline$k_{1}$ & $0,2540 \mathrm{~d}^{-1}$ \\
$\mathrm{k}_{d}$ & $0,3387 \mathrm{~d}^{-1}$ \\
$\mathrm{k}_{2}$ & $64,0746 \mathrm{~d}^{-1}$ \\
\hline
\end{tabular}

Fonte: AUTOR, 2015

Os cálculos realizados para obtenção dos coeficientes foram explicitados anteriormente segundo as tabelas 1 e 2 .

O valor de k1 está entre aqueles obtidos por Freire (2010) nos seus estudos da qualidade de água da bacia hidrográfica do Ribeirão Maringá. Os valores de $k_{2}$ mostraram-se bastante elevados devido a ocorrerem trocas gasosas, de modo bastante intenso, nas seções específicas 1 e 3 , principalmente pelo fato da pequena profundidade. Além disso, o leito do córrego se mostrava levemente encachoeirado, também principalmente na Seção1, proporcionando um aumento da oxigenação devido ao processo de turbilhonamento que a água sofre ao passar por esse leito.

Os valores de OD para as seções de controle, tanto com a aplicação da modelagem matemática, quanto com a amostragem de água e posterior trabalho em laboratório podem ser vistos nas Tabela 5.

Tabela 5: Resultados de oxigênio dissolvido ( $\mathrm{mg} / \mathrm{L}$ ) obtidos por meio da modelagem matemática e medidos em campo, para as seções de controle

\begin{tabular}{|c|c|c|c|}
\hline Seção de controle & OD modelagem (mg/L) & OD amostragem (mg/L) & Erro (\%) \\
\hline 3 & 7,07 & 6,95 & 1,73 \\
\hline 4 & 7,65 & 6,38 & 19,91 \\
\hline
\end{tabular}

Fonte: AUTOR, 2015

Os resultados relativos a DBO, para as seções de controle, estão dispostos na Tabela 6. Eles mostram valores obtidos com a aplicação do modelo, bem como com a amostragem. 


\section{Periódica Eletrânica

Tabela 6: Resultados de demanda bioquímica de oxigênio (mg/L) obtidos por meio da modelagem matemática e medidos em campo, para as seções de controle

\begin{tabular}{cccc}
\hline Seção de controle & DBO modelagem (mg/L) & DBO amostragem (mg/L) & Erro (\%) \\
\hline 3 & 8,93 & 10,00 & $-10,70$ \\
4 & 8,14 & 8,00 & 1,75 \\
\hline
\end{tabular}

Fonte: AUTOR, 2015

Nelas, ainda podem ser vistos os erros de estimativa relacionados à Modelagem Streeter \& Phelps (1925). Em relação ao oxigênio dissolvido, para o primeiro ponto de controle, pode-se perceber que o valor predito na modelagem matemática está bem próximo ao real (o valor real foi superestimado em 1,73\%), já a demanda bioquímica de oxigênio foi subestimada em 10,70\%. Para o segundo ponto de controle, o valor obtido através da modelagem para o OD está superestimado em $19,91 \%$ e para a DBO, em $1,75 \%$.

Os erros podem ser justificados pela formulação matemática utilizada modelar somente a depleção de oxigênio e reaeração do curso hídrico, sendo que, de acordo com Freire (2010), outros processos da dinâmica fluvial do Córrego do Limoeiro podem influenciar a autodepuração, assim problemas desse tipo são inerentes à modelagem matemática utilizada.

Como um dos resultados finais da aplicação da modelagem matemática, foram obtidos os perfis de oxigênio dissolvido e demanda bioquímica de oxigênio previstos, ambos em função da distância (figuras 2 e 3) e do tempo (figuras 4 e 5), respectivamente, para o Córrego do Limoeiro após o despejo do efluente tratado.

Figura 2: Perfil de OD previsto em função distância

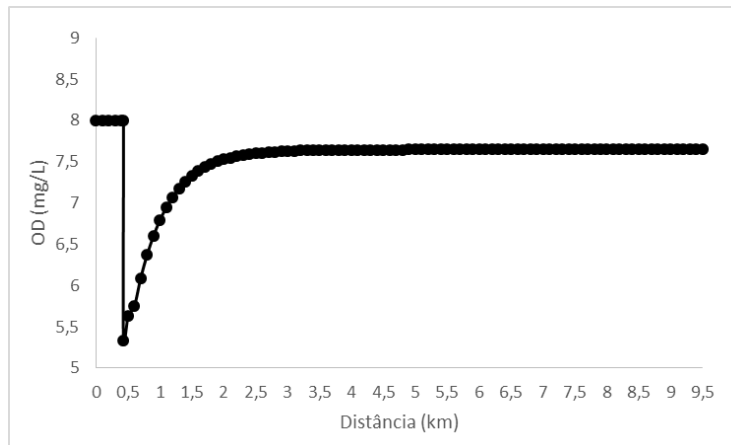

Fonte: AUTOR, 2015
Figura 3: Perfil de DBO previsto em função da da distância

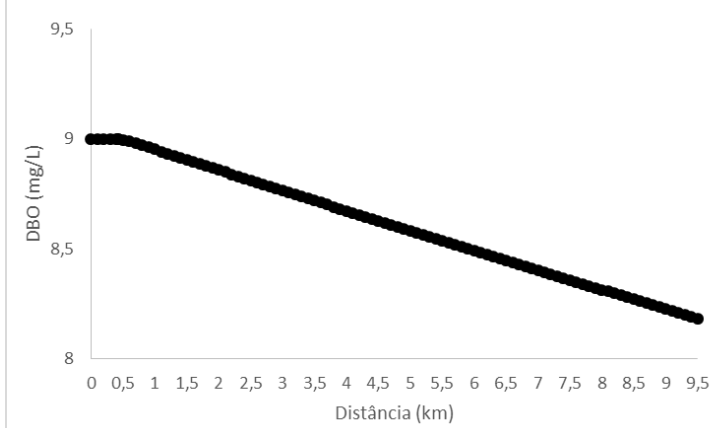

Fonte: AUTOR, 2015 
Figura 4: Perfil de OD previsto em função do tempo

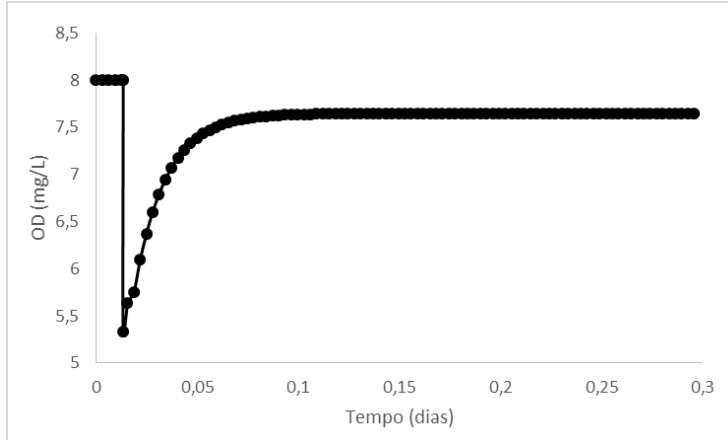

Fonte: AUTOR, 2015
Figura 5: Perfil de DBO previsto em função do tempo

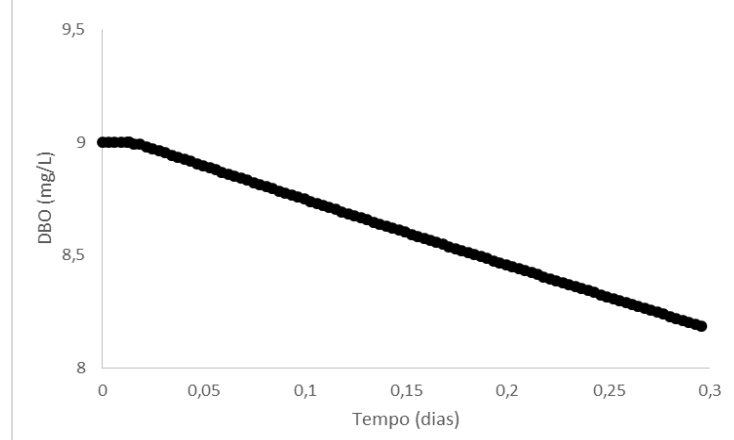

Fonte: AUTOR, 2015

As figuras 2 e 4 evidenciam a concentração de oxigênio dissolvido nas águas do corpo hídrico antes, durante e após o recebimento do efluente tratado pela Estação de Tratamento de Esgotos. Os gráficos começam pela Seção 1, considerando os dados a ela referentes, constantes até onde ocorre a mistura do efluente tratado com as águas do córrego. Para os perfis de DBO foi feita a mesma consideração.

Como pode ser visto, antes do lançamento do efluente tratado, o corpo d'água tem um OD de $8,00 \mathrm{mg} / \mathrm{L}$. Com o despejo de efluente, ocorre uma queda no valor dessa variável limnológica, até $5,33 \mathrm{mg} / \mathrm{L}$, porém isso não faz com o corpo hídrico esteja em desacordo com o OD mínimo permitido para a classe 4, na qual ele está enquadrado, que é de 2,00 mg/L, segundo a Resolução Conama N 357/05.

Scalize et. al (2004), estudando o processo de autodepuração do Ribeirão das Cruzes, obteve que os valores de OD começam a se recuperar apenas a partir de $5 \mathrm{~km}$ após o despejo do efluente tratado pela ETE Araraquara.

Pensando em termos da demanda bioquímica de oxigênio, segundo as figuras 3 e 5, após o lançamento do esgoto tratado, esta variável continua com o valor de $9,00 \mathrm{mg} / \mathrm{L}$ na mistura, valor este já obtido para a Seção 1 , por meio do monitoramento.

Passada a mistura, ocorre uma degradação da matéria orgânica remanescente de modo lento, tanto que pode ser observada nas figuras 3 e 5 , que para a distância até a qual a curva foi projetada, de $9,5 \mathrm{~km}$, num tempo equivalente a 0,3 dias, o valor correspondente a DBO chega a 8,19 mg/L.

Freire (2010), estudando a bacia hidrográfica do Ribeirão Maringá, na mesma época do ano, aplicando a modelagem Streeter \& Phelps (1925), obteve, 


\section{Periódica Eletranica

após a introdução de efluente tratado, valores de OD projetados crescentes ao longo do tempo e do espaço, chegando a serem maiores do que aqueles anteriores ao despejo dos efluentes.

Em relação as figuras acima, ainda podem ser diferenciadas as zonas de depuração da seguinte maneira: a zona de degradação já estaria ocorrendo antes do lançamento do efluente tratado, pois o corpo d'água já contém uma certa concentração (9 mg/L) de DBO, então a degradação de matéria orgânica já estaria ocorrendo mesmo antes da entrada do esgoto; a zona de decomposição ativa já poderia ser identificada no ponto de mistura do efluente com as águas do córrego, pois conforme as figuras 2 e 4, o OD mínimo é obtido nesse ponto; a zona de recuperação pode ser vista após o ponto de mistura, com a degradação da matéria orgânica remanescente e o aumento da concentração de OD; a zona de águas limpas não pode ser visualizada, pois a concentração de OD antes do lançamento não é completamente recuperada e o corpo d'água ainda possui uma quantidade de matéria orgânica a ser estabilizada.

Durante todo o trecho analisado, os valores de OD estão acima do permitido para a classe 4, na qual ele está enquadrado, que é de $2 \mathrm{mg} / \mathrm{L}$, segundo a Resolução Conama N 357/05.

\section{CONCLUSÃO}

É possível perceber que o Córrego do Limoeiro recebe uma carga de efluente condizente com seu porte, as concentrações de OD encontradas através da amostragem e com a aplicação da modelagem matemática mostram uma recuperação do corpo hídrico ao longo do tempo e do espaço.

Pode-se depreender que os valores encontrados, através da amostragem e aqueles obtidos com a aplicação da modelagem, para as seções de controle, são diferentes. Isso se deu por erros que estão embutidos na própria amostragem e são de difícil quantificação, além disso, a formulação matemática utilizada modela somente a depleção de oxigênio e reaeração do curso hídrico, sendo que, outros processos podem influenciar na autodepuração. Porém, para uma análise preliminar do curso d'água em questão, a formulação se mostra bastante eficiente, pois mostra de maneira confiável os dois parâmetros modelados. 


\section{REFERÊNCIAS BIBLIOGRÁFICAS}

ANDRADE, L. N. Autodepuração dos corpos d'água. Vitória, 2010. Disponível em: <http://www.ib.usp.br/revista/node/45>. Acessado em: 20 fev. 2015.

BARROS et al. Reoxigenação e desoxigenação no Rio Turvo Sujo. Viçosa, 2011. Disponível em: <http://www.conhecer.org.br/enciclop/2011a/ambientais/reoxigenacao.pdf >. Acessado em: 16 jan. 2015.

BARRUS, E. P. A. Autodepuração de Corpos d'água. Anápolis, 2009. Disponível em: <http://epabarrus2005.blogspot.com/2009/07/autodepuracao-dos-cursos-dagua.html>. Acesso em: 15 jan. 2015.

BRAGA, B. et al. Introdução à Engenharia Ambiental: O Desafio do Desenvolvimento Sustentável. 2 ed. São Paulo: Pearson, 2005. 305 p.

BRASIL. Resolução Conama N 357, de 17 de março de 2005. Dispõe sobre a classificação dos corpos de água e diretrizes ambientais para o seu enquadramento, bem como estabelece as condições e padrões de lançamento de efluentes, e dá outras providências. Disponível em: <http://www.mma.gov.br/port/conama/res/res05/ res35705.pdf>. Acessado em: 19 fev. 2015.

FREIRE, R. Monitoramento da qualidade da água da bacia hidrográfica do Ribeirão Maringá. 2010. 175 f. Dissertação (Mestrado em Engenharia Química) - Universidade Estadual de Maringá, Maringá. Disponível em: <http://nou-rau.uem.br/nou-rau/document/?code=vtls000178860>. Acessado em: 27 dez. 2014.

FREIRE, R. S. Autodepuração de corpos d'água: 1ำ semestre. São Paulo, 2008. Disponível em: <http://www.usp.br/gpqa/Disciplinas/qfl2637/Aula1_aguap4.pdf>. Acessado em: 12 fev. 2015.

MOTA, S. Introdução à Engenharia Ambiental. 3 ed. Rio de Janeiro: ABES, 2003. 419 p.

MOURÃO JÚNIOR. P. R. Aplicação do modelo de autodepuração de qualidade das águas QUAL-UFMG: Estudo de caso sub-bacia do Rio Piracicaba. 2010. 160 f. Dissertação (Mestrado em Sustentabilidade socioeconômica e ambiental) - Universidade Federal de Ouro Preto, Ouro Preto. Disponível em: <http://www.sustentabilidade.ufop.br/arquivos/dis/2010/ Polynice\%20Mourao.pdf>. Acessado em: 21 jan. 2015.

SANTOS, A. R. Caracterização morfológica, hidrológica e ambiental da bacia hidrográfica do Rio Turvo Sujo, microrregião de Viçosa, MG. 2001. 143 f. Dissertação (Mestrado em Engenharia agrícola) - Universidade Federal de Viçosa, Viçosa. Disponível em: $<$ http://www.mundogeomatica.com.br/TesesMonografi as/Tese_Site/Tese_Doutorado_Prof_Alexandre_Rosa_Santos.pdf >. Acessado em: 22 jan. 2015.

SÃO PAULO. Decreto N 10.755, de 22 de novembro de 1977. Dispõe sobre o enquadramento dos corpos de água receptores na classificação prevista no Decreto no 8.468 , de 8 de setembro de 1976, e dá providências correlatas. Disponível em: < http://www.cetesb. sp.gov.br/licenciamentoo/legislacao/estadual/decretos/1997__Dec_Est_10755.pdf>. Acessado em: 19 fev. 2015.

SCALIZE, P. S. et al. Avaliação da autodepuração do Ribeirão das Cruzes através da depressão do oxigênio dissolvido após receber efluente da ETE-Araraquara. Disponível em: <http://www.bvsde.paho.org/ bvsacd/assemae/rrhh/araraquara.pdf>. Acessado em: 19 fev. 2015.

VON SPERLING, M. Estudos e modelagem da qualidade da água e de rios. 1 ed. Belo Horizonte: DESA-UFMG, 2007. v. 7. 588 p.

VON SPERLING, M. Introdução à qualidade das águas e ao tratamento de esgotos. 3 ed. Belo Horizonte: DESA-UFMG, 2005. v. 1. 452 p. 